\title{
Evolution mechanism of recrystallization in a nickel-based single crystal superalloy under various cooling rates during heat treatment
}

\author{
Yong-shun Li', *Wei-dong Xuan', Jian Yang', Yu-hao Zhou', * Ge Song ${ }^{\mathbf{2}}$, Xing-fu Ren ${ }^{1}$, and Zhong-ming Ren ${ }^{1}$ \\ 1. State Key Laboratory of Advanced Special Steel \& Shanghai Key Laboratory of Advanced Ferrometallurgy \& School of Materials \\ Science and Engineering, Shanghai University, Shanghai 200444, China \\ 2. School of Medicine, Shanghai University, Shanghai 200444, China
}

\begin{abstract}
The recrystallization behaviors of a nickel-based single crystal superalloy during heat treatment at $1,200{ }^{\circ} \mathrm{C}$ for $4 \mathrm{~h}$ with various cooling rates were studied. Results show that the thickness of recrystallization layer decreases with the increase of cooling rate. In addition, the microstructures of $\mathrm{Y}^{\prime}$ phase in the recrystallization region are different in various cooling rates. In the high cooling rates $\left(70,100{ }^{\circ} \mathrm{C} \cdot \mathrm{min}^{-1}\right)$, small size and high volume fraction of $\gamma^{\prime}$ phases are formed in the recrystallization region. It is also found that irregular fine secondary $\gamma^{\prime}$ phases are precipitated between matrix channels with an average size of $150 \mathrm{~nm}$ in the original matric $\left(100{ }^{\circ} \mathrm{C} \cdot \mathrm{min}^{-1}\right)$. The sizes of the secondary $\gamma^{\prime}$ phase decrease with the increase of cooling rate. In contrast, large size and small volume fraction of $\mathrm{Y}^{\prime}$ phases are formed in the recrystallization region, and a grain boundary layer is formed under a low cooling rate $\left(10^{\circ} \mathrm{C} \cdot \mathrm{min}^{-1}\right)$. The evolution mechanism of recrystallization at various cooling rates during heat treatment is analyzed.
\end{abstract}

Keywords: recrystallization; cooling rate; $\mathrm{Y}^{\prime}$ phase; single crystal superalloy

CLC numbers: TG132.3 3 Document code: A

Article ID: $1672-6421(2022) 01-027-08$

\section{Introduction}

Nickel-based single crystal (SX) superalloy is widely used in aero-engine turbine blades due to its excellent high-temperature performance and comprehensive performance ${ }^{[1]}$. It is well known that residual stresses generated during the removal of shell and cores can easily cause the formation of recrystallization layer on the surface of SX superalloy during heat treatment ${ }^{[2-6]}$. Due to the introduction of new grain boundaries (GBs) caused by the formation of recrystallization, the mechanical properties of SX superalloy are significantly decreased ${ }^{[7-12]}$. Jo et al. ${ }^{[7]}$ reported that the early initiation of surface cracks in recrystallized specimens at $982{ }^{\circ} \mathrm{C}$ and $240 \mathrm{MPa}$ could reduce creep life. Meng et al. ${ }^{[13]}$

\section{*Wei-dong Xuan}

Male, Ph. D, Associate Professor. His research interests mainly focus on microstructure analysis, high-temperature mechanical performance and casting process control of nickel-based single crystal superalloy, and ceramic core technology development.

E-mail: wdxuan@shu.edu.cn

*Ge Song

E-mail: gesong@shu.edu.cn

Received: 2021-04-20; Accepted: 2021-12-14 found that the creep rupture life was decreased with the increase of recrystallization depth deformed by shot peening in the alloy. Ma et al. ${ }^{[14]}$ found that the fatigue life of SX superalloy was obviously decreased by local recrystallization. These fatigue cracks preferred to form initially from local recrystallized grains, and propagated along the recrystallized grains. Shi et al. ${ }^{[15]}$ reported that the recrystallized grain boundaries could act as the channels for the crack initiation and propagation during tensile test. It was also found that the decrease of tensile properties was attributed to the local stress concentration caused by recrystallized layers.

To understand the formation mechanism of recrystallization in the SX, researchers conducted a lot of studies on recrystallization. Xiong et al. ${ }^{[16]}$ and Zambaldi et al. ${ }^{[17]}$ found that heat treatment temperature and soaking time were critical for the recrystallization in the SX. The increase of heat treatment temperature and soaking time promoted the nucleation activation energy of recrystallization. Xie et al. ${ }^{[18]}$ investigated the orientational dependence of recrystallization in SX superalloy, indicating that a large displacement was generated along the $<011>$ direction of the $(100)$ indentation, while only small pile-ups were observed around the (110) indentation. Wang et al. ${ }^{[19,20]}$ 
studied the effect of carbides on the nucleation and growth of recrystallization, and found that carbides could act as the nucleation sites of recrystallized grains and inhibit the migration of recrystallization grain boundaries by various pinning mechanisms. Li et al. ${ }^{[21]}$ reported that the deformation temperature and annealing conditions significantly influenced the recrystallization behavior in the SX superalloy. It was also found that stacking faults promoted the formation of recrystallization by thermal twinning nucleation. Cox et al. ${ }^{[22]}$ also found that the plastic deformation was introduced using an electrothermal mechanical test (ETMT) machine at high temperatures for CMSX-4 superalloy, and the recrystallization of samples easily occurred during annealing at $1,225^{\circ} \mathrm{C}$. Instead, the equivalent strain was introduced at room temperature for CMSX-4 superalloy to figure out its effect for recrystallization, while no recrystallization was observed at an annealing temperature of $1,260{ }^{\circ} \mathrm{C}$ or below. These results were attributed to the high strength of $\gamma^{\prime}$ particles. This strength at room temperature was higher than that of the matrix at elevated temperatures when the strain was introduced, leading to the increase of dislocation density and driving force for the nucleation of recrystallization. Recently, some investigations indicated that the microstructure and high temperature mechanical properties of SX superalloy were obviously influenced by the cooling rate after heat treatment ${ }^{[2,24]}$, while the investigation of recrystallization was mainly focused on heat treatment temperature and soaking time, deformation temperature and annealing condition, orientation dependence and microstructure characteristics ${ }^{[16-22]}$. An in-depth study is necessary to understand the effect of cooling rate on the recrystallization of SX superalloy during heat treatment.

In this work, the evolution mechanism of recrystallization of SX superalloy under various cooling rates during heat treatment was studied. The distribution of recrystallization elements was characterized using electron probe microanalysis (EPMA), and the element migration process under various cooling rates was discussed to reveal the microstructure evolution of SX superalloy.

\section{Experimental procedure}

A second-generation SX superalloy was employed. The element content is shown in Table 1 . The cylindrical single crystal bar with the size of $\Phi 16 \mathrm{~mm} \times 200 \mathrm{~mm}$ was prepared in a Bridgman furnace.

Table 1: Element content of alloys (wt.\%)

\begin{tabular}{ccccccccccccc} 
Cr & Co & Mo & W & Ta & Re & Nb & Al & Hf & C & Ni \\
\hline 4.3 & 9.0 & 2.0 & 8.0 & 7.5 & 2.0 & 0.5 & 5.6 & 0.1 & 0.006 & Bal.
\end{tabular}

According to previous report, an uneven microstructure was observed in the as-cast superalloy and some eutectics were found, influencing the formation of recrystallization ${ }^{[25]}$. In this work, heat treatment for all samples was conducted to eliminate the influence of eutectics on recrystallization ${ }^{[26]}$. The heat treatment procedure was as follows ${ }^{[27]}: 1,290{ }^{\circ} \mathrm{C} / 1 \mathrm{~h}+$ $1,300{ }^{\circ} \mathrm{C} / 2 \mathrm{~h}+1,315{ }^{\circ} \mathrm{C} / 4 \mathrm{~h} / \mathrm{AC}+1,120{ }^{\circ} \mathrm{C} / 4 \mathrm{~h} / \mathrm{AC}+870{ }^{\circ} \mathrm{C} /$ $32 \mathrm{~h} / \mathrm{AC}$. Then, the samples were cut into cylinders with a height of $6 \mathrm{~mm}$ and a diameter of $6 \mathrm{~mm}$ by electro discharge machining. Finally, they were mechanically ground and polished to obtain a smooth surface. Brinell hardness tester with a load of $98 \mathrm{MPa}$ was applied to perform indentation deformation treatment on the surface along the [001] crystallographic plane [Fig. 1(a)]. To study the recrystallization behavior of the indented cylinder sample, further heat treatments with various cooling rates $\left(10,70\right.$, and $\left.100^{\circ} \mathrm{C} \cdot \mathrm{min}^{-1}\right)$ were conducted at $1,200^{\circ} \mathrm{C}$ for $4 \mathrm{~h}$, as shown in Fig. 1(b). (a)

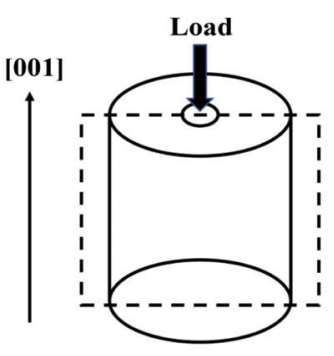

(b)

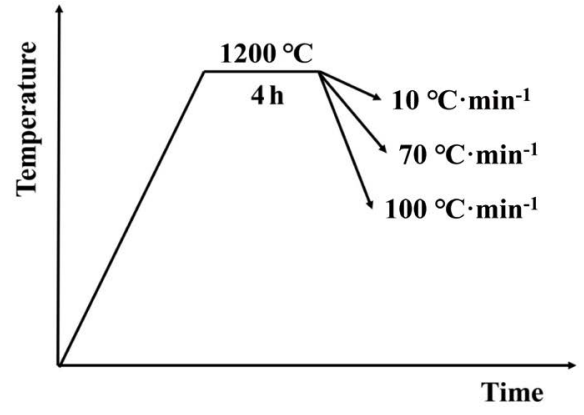

Fig. 1: Schematic of indented sample (a) and experimental procedure (b)

The samples were cut parallel to the [001] direction along the center as shown in Fig. 1(a). Then, they were mechanically ground, polished and etched. The microstructures of the samples were observed with FEI-Quanta 450 scanning electron microscopy, and the recrystallization was observed with electron backscatter diffraction (EBSD) technique. In addition, the element distribution of the recrystallization region was detected with an electron probe micro-analyzer (EPMA). Finally, ImageJ software was used to measure and calculate the average size and volume fraction of $\gamma^{\prime}$ phases. 


\section{Results}

\subsection{Recrystallization microstructure under various cooling rates}

Figure 2 shows the macroscopic morphologies of recrystallization under various cooling rates obtained by EBSD. It is found that a continuous recrystallization layer is formed on the surface of SX superalloy, and the average thickness of the recrystallization layer decreases with the increase of cooling rate.

\subsubsection{Microstructure in recrystallization region}

Figure 3 shows the microstructure and size distribution of $\gamma^{\prime}$ phase in recrystallization ( $\mathrm{RX}$ ) region under various cooling rates. It can be found that the cooling rate has ovbious effect on size and morphology of the $\gamma^{\prime}$ phase. At a cooling rate of $10{ }^{\circ} \mathrm{C} \cdot \mathrm{min}^{-1}$, the $\gamma$ matrix phase between $\gamma^{\prime}$ phases is very thin and has a tendency to merge into coarse $\gamma^{\prime}$ phase with an average size of $600 \mathrm{~nm}$. As the cooling rate increases to $70{ }^{\circ} \mathrm{C} \cdot \mathrm{min}^{-1}$, the morphology of $\gamma^{\prime}$ phase is cubic, and the average size decreases to $150 \mathrm{~nm}$. When the cooling rate
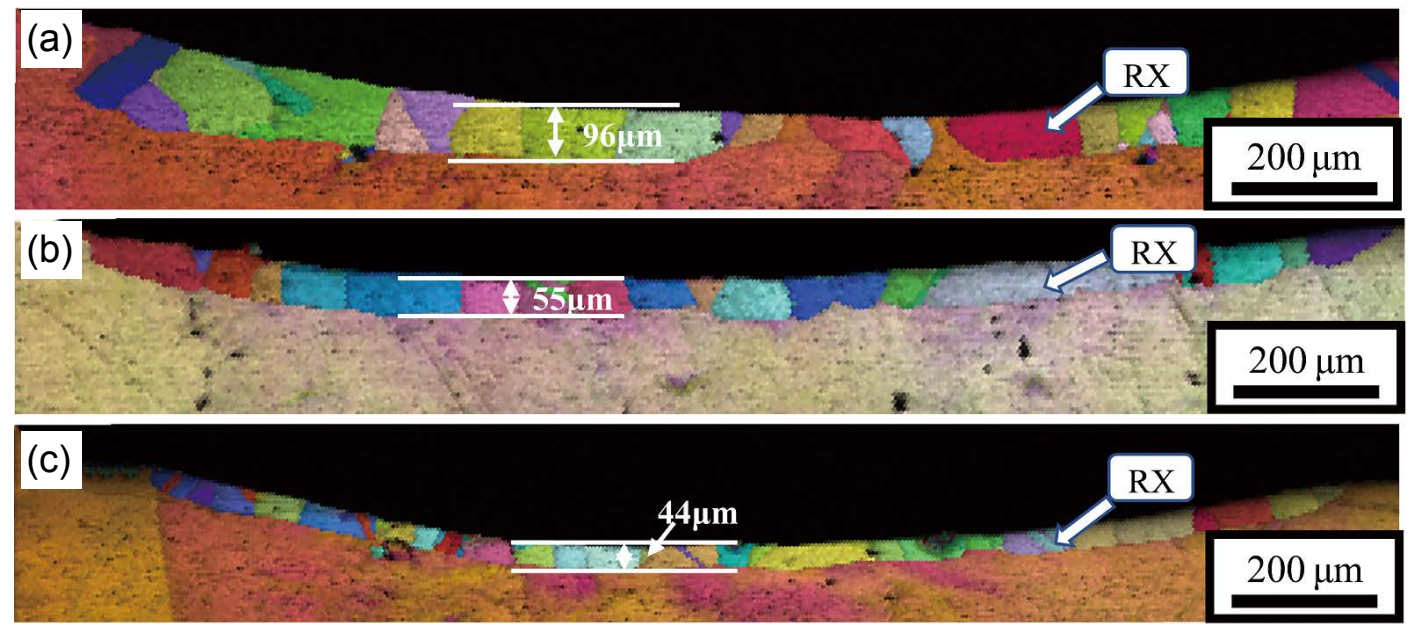

Fig. 2: EBSD diagrams of recrystallization under different cooling rates: (a) $10^{\circ} \mathrm{C} \cdot \mathrm{min}^{-1}$; (b) $70^{\circ} \mathrm{C} \cdot \mathrm{min}^{-1}$; (c) $100^{\circ} \mathrm{C} \cdot \mathrm{min}^{-1}$
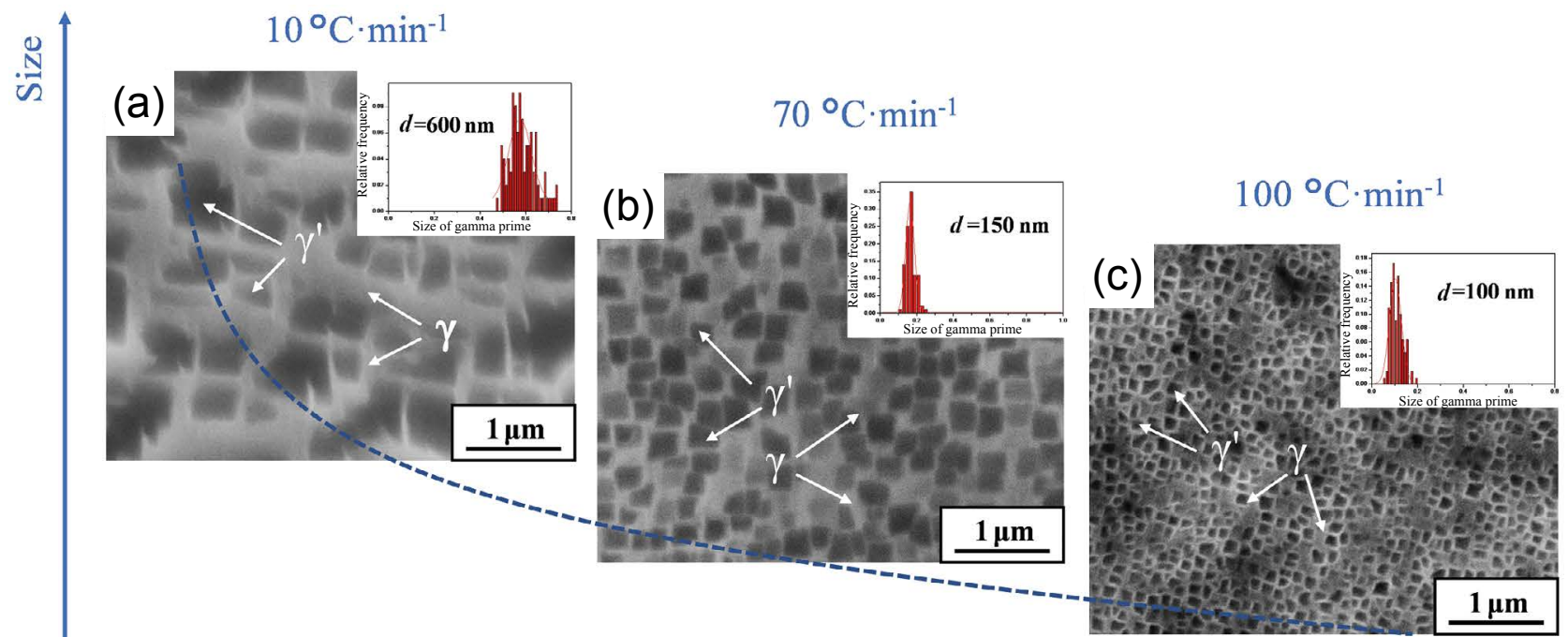

Cooling rate

Fig. 3: Microstructure and size distribution of $\mathrm{Y}^{\prime}$ phases in recrystallization region under various cooling rates: (a) $10^{\circ} \mathrm{C} \cdot \mathrm{min}^{-1}$; (b) $70^{\circ} \mathrm{C} \cdot \mathrm{min}^{-1}$; (c) $100^{\circ} \mathrm{C} \cdot \mathrm{min}^{-1}$

further increases to $100{ }^{\circ} \mathrm{C} \cdot \mathrm{min}^{-1}$, the $\gamma^{\prime}$ phase is still in cubic shape, but the average size decreases to about $100 \mathrm{~nm}$ and the number increases significantly. The volume fraction and average size of $\gamma^{\prime}$ phases calculated using ImageJ are shown in Fig. 4. The results mentioned above indicate that the average size of $\gamma^{\prime}$ phase decreases and shows a logarithmic relationship with the increase of cooling rate, which can be expressed as ${ }^{[28]}$. $\mathrm{g} D_{\gamma^{\prime}}=2.4128-0.3266 \times \lg (\mathrm{d} T / \mathrm{d} t) ; R^{2}=0.99$, where $D_{\gamma^{\prime}}$ represents the average size of $\gamma^{\prime}$ phases, and $\mathrm{d} T / \mathrm{d} t$ represents the cooling rate.

\subsubsection{Microstructure in original matrix of SX superalloy}

Figure 5 shows the microstructure of the original matrix in front of recrystallization under various cooling rates. These micrographs show that the primary $\gamma^{\prime}$ phase is coarse and 


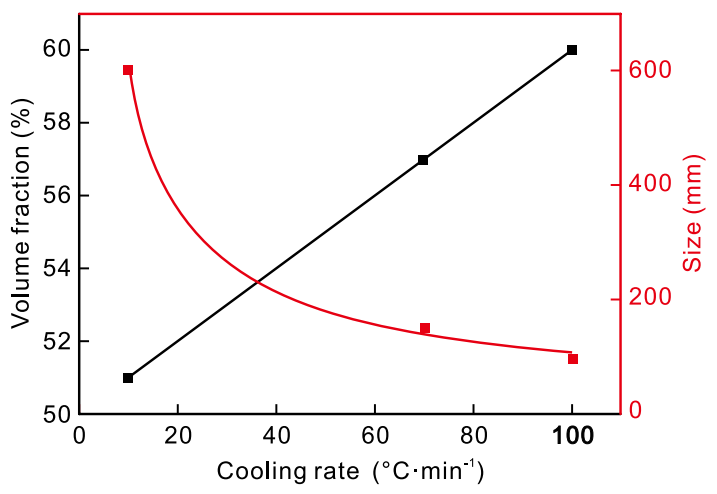

Fig. 4: Average size and volume fraction of $Y^{\prime}$ phases inside recrystallization under various cooling rates irregular at a low cooling rate. The $\gamma$ matrix channels between some primary $\gamma^{\prime}$ phases are narrow or disconnected, indicating that primary $\gamma^{\prime}$ phases grow and coarsen by merging. When the cooling rate is increased from 10 to $70{ }^{\circ} \mathrm{C} \cdot \mathrm{min}^{-1}$, the primary $\gamma^{\prime}$ phases are refined, many fine secondary $\gamma^{\prime}$ phases are precipitated with an average size of $150 \mathrm{~nm}$, and the morphologies are irregular. When the cooling rate reaches $100{ }^{\circ} \mathrm{C} \cdot \mathrm{min}^{-1}$, the sizes of the primary and secondary $\gamma^{\prime}$ phases decrease. The average size of the secondary $\gamma^{\prime}$ phase is about $80 \mathrm{~nm}$, the number increases, and their morphologies are cuboidal or triangular. Therefore, the morphology and size of the primary and secondary $\gamma^{\prime}$ phases of original matrix in front of recrystallization are mainly controlled by cooling rate.
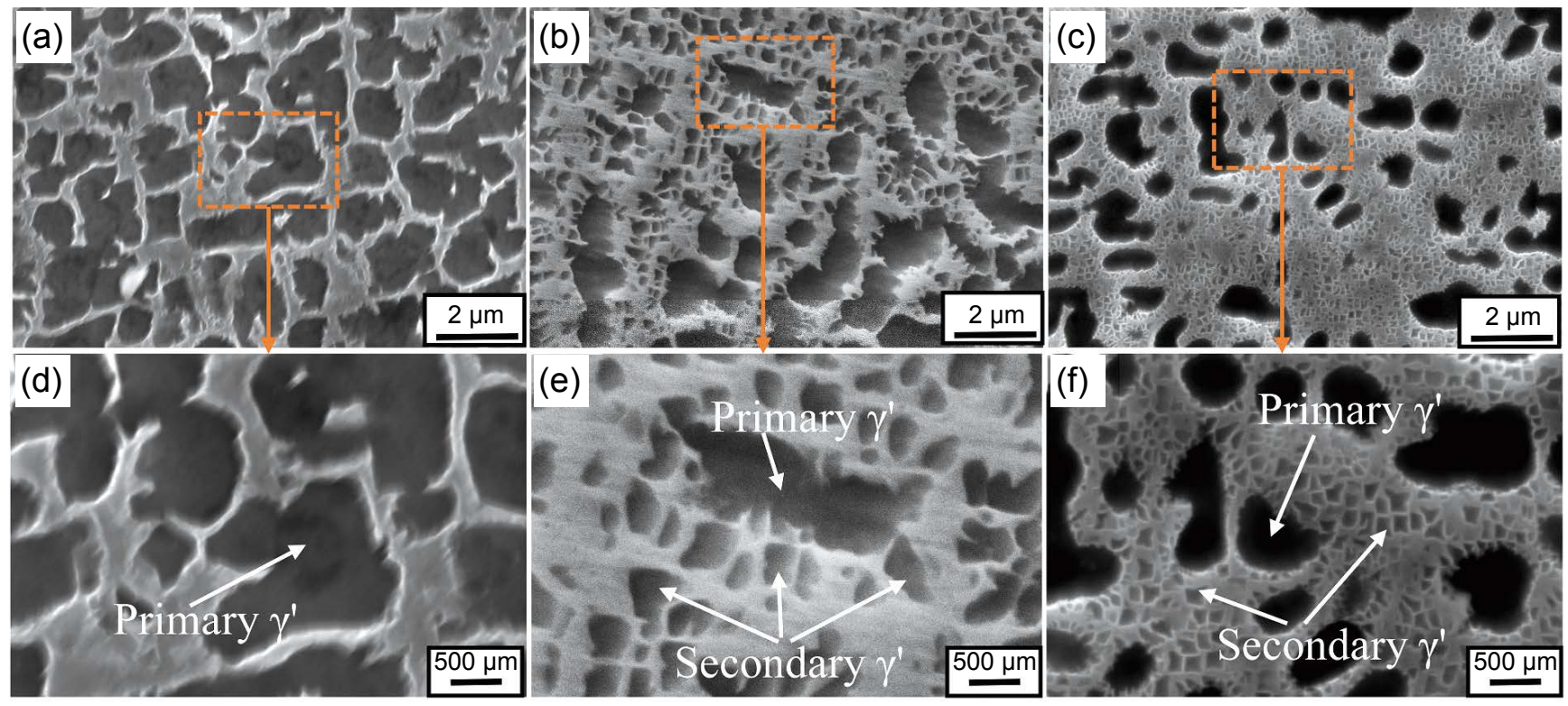

Fig. 5: Microstructures in original matrix under various cooling rates: $(\mathrm{a}, \mathrm{d}) 10^{\circ} \mathrm{C} \cdot \mathrm{min}^{-1} ;(\mathrm{b}, \mathrm{e}) 70^{\circ} \mathrm{C} \cdot \mathrm{min}^{-1}$; (c, f) $100^{\circ} \mathrm{C} \cdot \mathrm{min}^{-1}$

\subsection{Evolution of recrystallization grain boundary under various cooling rates}

Figure 6 shows the microstructure of the recrystallization GBs under various cooling rates. The recrystallization GB layers with a thickness of $400 \mathrm{~nm}$ are found at a low cooling rate of $10{ }^{\circ} \mathrm{C} \cdot \mathrm{min}^{-1}$, while they are not observed at cooling rates of 70 and $100^{\circ} \mathrm{C} \cdot \mathrm{min}^{-1}$.

To clarify the mechanism of recrystallization and microstructure evolution under various cooling rates, EPMA mapping scanning was used to analyze the composition distribution of the alloys, as shown in Fig. 7. Results show that $\mathrm{Cr}, \mathrm{Co}, \mathrm{W}, \mathrm{Mo}$ and Re are enriched in the $\gamma$ matrix phase, and $\gamma^{\prime}$ phase mainly contains Al, Ta and Ni. GBs can be clearly distinguished by different composition distributions on both sides. Of particular note, a continuous GB layer that mainly contains $\mathrm{Cr}, \mathrm{Co}, \mathrm{Mo}, \mathrm{Re}$ is formed at a low cooling rate, $\mathrm{Al}$,
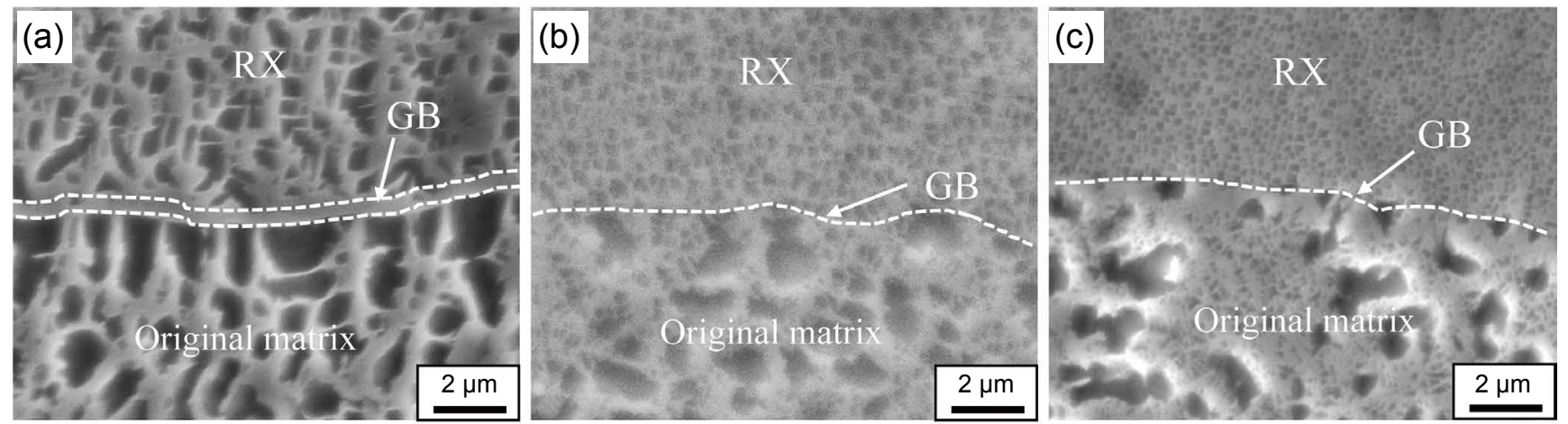

Fig. 6: Microstructures of recrystallization GBs under different cooling rates: (a) $10^{\circ} \mathrm{C} \cdot \mathrm{min}^{-1}$; (b) $70^{\circ} \mathrm{C} \cdot \mathrm{min}^{-1} ;$ (c) $100{ }^{\circ} \mathrm{C} \cdot \mathrm{min}^{-1}$ 

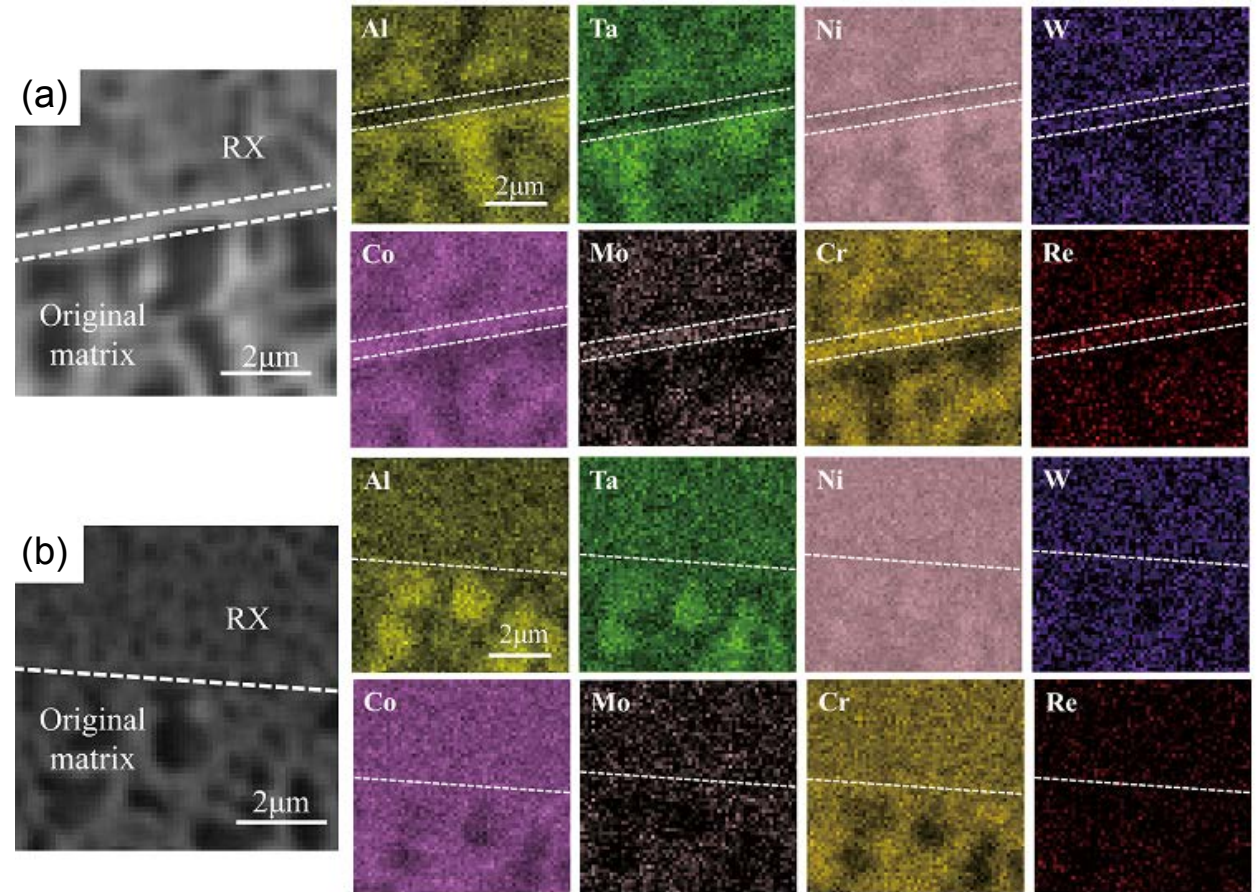

$\operatorname{Re}$
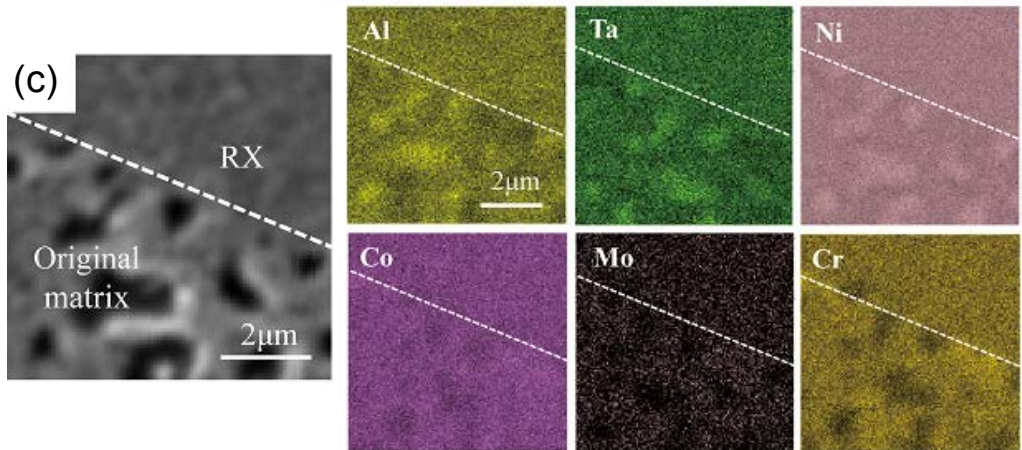

Mo
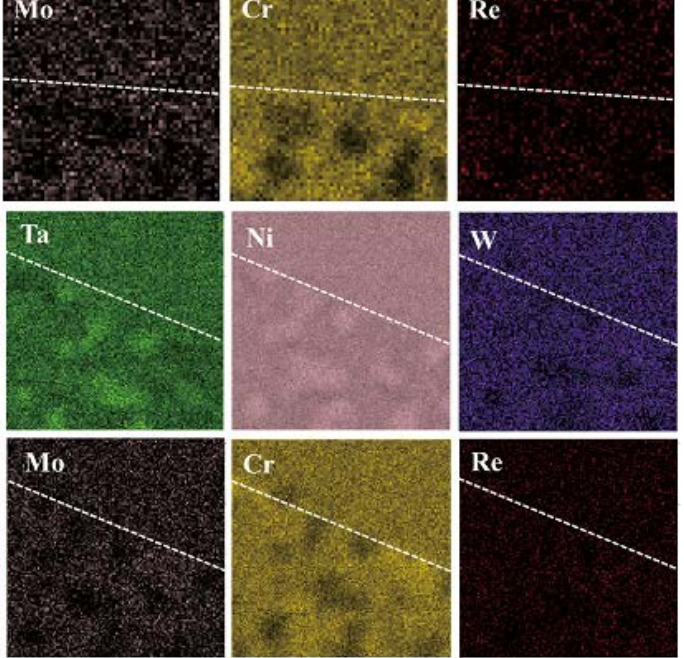

Fig. 7: Results of EPMA map scanning under various cooling rates: (a) $10^{\circ} \mathrm{C} \cdot \mathrm{min}^{-1}$; (b) $70^{\circ} \mathrm{C} \cdot \mathrm{min}^{-1}$; (c) $100{ }^{\circ} \mathrm{C} \cdot \mathrm{min}^{-1}$

$\mathrm{Ta}$, and $\mathrm{Ni}$ elements are depleted, and $\mathrm{W}$ remains unchanged. This is similar to the matrix phase, but the contents of $\mathrm{Cr}$ and Co in matrix phase are vast which is different from the results obtained at the high cooling rates.
The element distribution on both sides of GB also changes with cooling rate. Table 2 shows the element contents calculated under different cooling rates through EPMA point scanning. It is found that the contents of $\gamma^{\prime}$ phase forming

Table 2: Element contents in recrystallization, GB and original matrix (OM)

\begin{tabular}{|c|c|c|c|c|c|}
\hline \multirow{2}{*}{$\begin{array}{l}\text { Cooling rate } \\
\left({ }^{\circ} \mathrm{C} \cdot \mathrm{min}^{-1}\right)\end{array}$} & \multirow{2}{*}{ Location } & \multicolumn{4}{|c|}{ Element content (wt.\%) } \\
\hline & & Al & Ta & $\mathrm{Cr}$ & Co \\
\hline \multirow{3}{*}{10} & Recrystallization & 4.38 & 8.14 & 3.95 & 8.66 \\
\hline & GB layer & 2.71 & 6.71 & 6.04 & 10.97 \\
\hline & Original matrix & 4.69 & 8.48 & 3.07 & 8.03 \\
\hline \multirow{3}{*}{70} & Recrystallization & 4.74 & 8.66 & 3.81 & 8.49 \\
\hline & GB layer & - & - & - & - \\
\hline & Original matrix & 4.18 & 8.01 & 3.28 & 8.28 \\
\hline \multirow{3}{*}{100} & Recrystallization & 5.12 & 9.23 & 3.65 & 8.38 \\
\hline & GB layer & - & - & - & - \\
\hline & Original matrix & 3.92 & 7.92 & 3.31 & 8.22 \\
\hline
\end{tabular}


elements such as Al and Ta increase with the increase of cooling rate in the recrystallization region, while the contents of $\mathrm{Cr}$ and Co decrease (Table 2), and the results are different in the original matrix.

\section{Discussion}

\subsection{Nucleation and growth of recrystallization}

Nucleation is the initial stage of the recrystallization process and critical to the subsequent growth of recrystallization. For plastically deformed superalloy, the load applied to the superalloy contains a part of deformation energy in the form of dislocations, which is also the driving force for recrystallization during heating ${ }^{[29]}$. Recrystallization is formed only when the driving force is higher than the critical value which can be expressed as ${ }^{[30]}$ :

$$
p^{c}=\frac{10^{7} \varepsilon_{c}}{2.2 \varepsilon_{c}+1.1} \gamma_{\mathrm{lagb}}
$$

where $\varepsilon_{\mathrm{c}}$ is the critical plastic strain $\left(6 \%\right.$ in this study $\left.{ }^{[31]}\right)$, and $\gamma_{\text {lagb }}$ is the low angle grain boundary energy, which is $0.6 \mathrm{~J} \cdot \mathrm{m}^{-3}{ }^{[31]}$. Then, the critical driving force for recrystallization is calculated according to Eq. (1), which is about 0.29 $\mathrm{MPa}$. Humphreys et al. ${ }^{[32]}$ found that most of the work consumed in deforming a superalloy was released as heat and only a very small amount $(\sim 1 \%)$ remained as energy (driving force for recrystallization) in the material. For the present experiment, the applied stress is $98 \mathrm{MPa}$, the corresponding recrystallization driving force is about $0.98 \mathrm{MPa}$ according to the report of Humphreys et al., which is higher than the critical driving force for recrystallization $(0.29 \mathrm{MPa})$. As a result, recrystallization is formed during heat treatment.

After the nucleation of recrystallization, GB migrates into the original matrix to promote the recrystallization. The recrystallization growing process is mainly controlled by the GB mobility, $M$, which is generally expressed by the Arrhenius relation ${ }^{[33]}$ :

$$
M=M_{0} \exp \left(-\frac{Q_{\mathrm{b}}}{R T}\right)
$$

where $M_{0}$ is the recrystallization GB mobility constant, $Q_{\mathrm{b}}$ is the activation energy for GB motion, $R$ is the universal gas constant, and $T$ is the temperature. According to Eq. (2), the recrystallization GB mobility is increased with the increase of temperature, $T$. The heat treatment temperature and holding time are constant in this study $\left(1,200{ }^{\circ} \mathrm{C}, 4 \mathrm{~h}\right)$, while the cooling rate is variable. Therefore, the different thickness of recrystallization layer should be attributed to cooling rate.

As it is known, the recrystallization GB has a relatively loose structure, and the bonds between atoms are severed or severely distorted, resulting in high energies at the interface. Therefore, the elements tend to spontaneously segregate to the GB. The elements enriched in the recrystallization GB produce a drag force on the migration of the $\mathrm{GB}$, and the drag force mainly depends on the concentration of elements on the GB ${ }^{[34]}$. At a low cooling rate $\left(10{ }^{\circ} \mathrm{C} \cdot \mathrm{min}^{-1}\right)$, the temperature drops slowly, and the recrystallization GB still has a fast migration speed, promoting the rapid growth of recrystallization. In addition, elements have sufficient time to diffuse, and the diffusion rate along the GB is faster than the rate of intragranular diffusion, thereby promoting the diffusion of the elements on $\mathrm{GB}^{[34]}$. Finally, the recrystallization GB segregation effect is weakened, and the element concentration in the GB is decreased, resulting in the decrease of the drag force of the elements on GB. It further promotes the rapid migration of the recrystallization GB to the original matrix, forming a thick recrystallization layer [Fig. 8(a-c)]. At high cooling rates (70 and $100{ }^{\circ} \mathrm{C} \cdot \mathrm{min}^{-1}$ ), the temperature drops rapidly, leading to a decrease in the migration speed of the recrystallization GB, and inhibits the growth of recrystallization. Moreover, the diffusion of the elements is inhibited due to the insufficient element diffusion time ${ }^{[35]}$, resulting in the element enrichment in the recrystallization GB. The element segregation in the

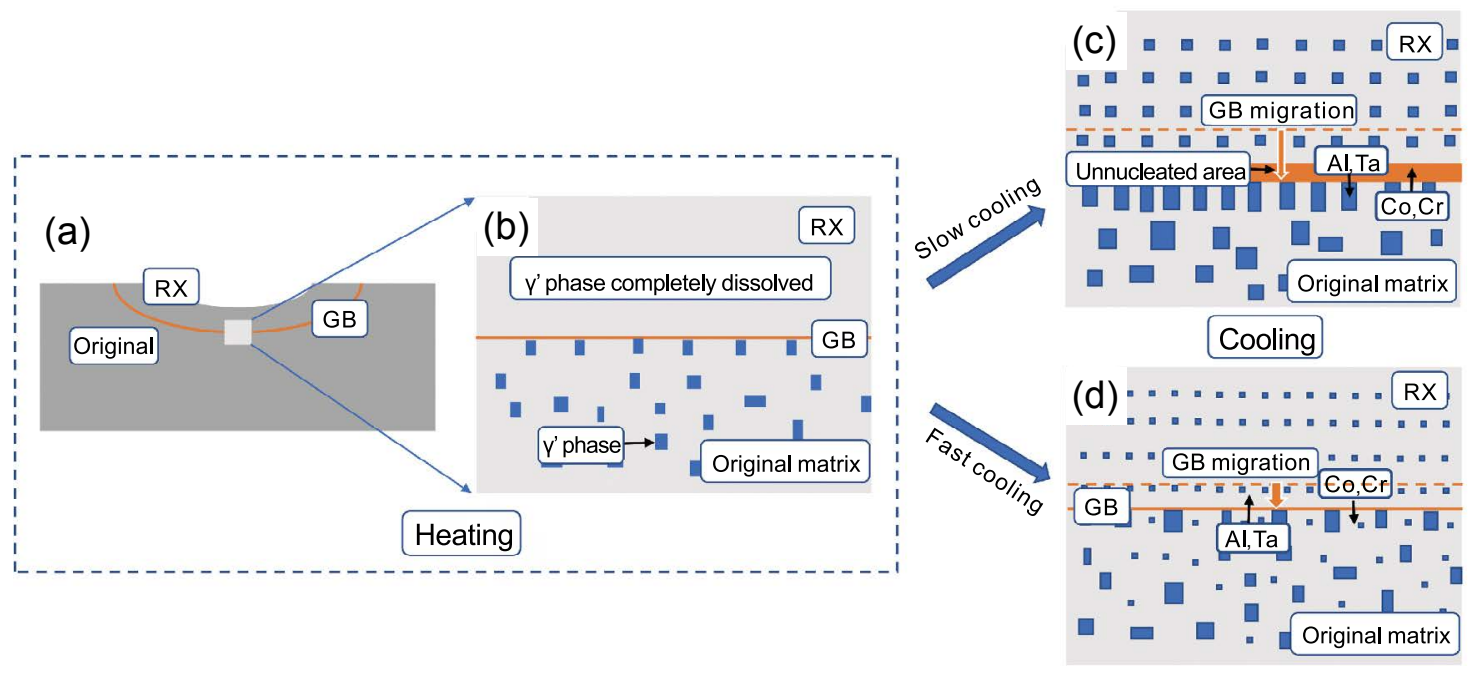

Fig. 8: Schematic diagram of recrystallization evolution under various cooling rates: (a-b) heating process; (c) slow cooling; (d) fast cooling 
recrystallization $\mathrm{GB}$ is severe, and the drag force of the elements on GB is enhanced, thereby hindering the migration of the recrystallization GB to the original matrix and forming a thin recrystallization layer, as shown in Fig. 8(a, b, d).

\section{$4.2 y^{\prime}$ phase evolution of recrystallization}

It can be seen from Fig. 6 that the size and morphology of $\gamma^{\prime}$ phase in the recrystallization region are different under various cooling rates. Mao et al. ${ }^{[36]}$ reported that the acceleration of cooling rate would increase the undercooling degree, thereby reducing the nucleation energy barrier and promoting the nucleation of $\gamma^{\prime}$ phase. In this work, at a low cooling rate $\left(10^{\circ} \mathrm{C} \cdot \mathrm{min}^{-1}\right)$, the energy barrier for the nucleation of $\gamma^{\prime}$ phase is high, and it is not easy to nucleate, resulting in a small amount of $\gamma^{\prime}$ phases in the recrystallization region [Fig. 8(c)]. The elements in the recrystallization region have sufficient time to diffuse to promote the growth of $\gamma^{\prime}$ phase. Therefore, the size of $\gamma^{\prime}$ phase is large in the recrystallization region. At high cooling rates $\left(70\right.$ and $\left.100{ }^{\circ} \mathrm{C} \cdot \mathrm{min}^{-1}\right)$, the energy barrier for nucleation of $\gamma^{\prime}$ phase is low, and it is easy to nucleate ${ }^{[37]}$, but the elements do not have enough time to diffuse ${ }^{[38]}$, resulting in a large amount of small $\gamma^{\prime}$ phases in the recrystallization region [Fig. 8(d)].

According to the analyses in Section 4.1, it is shown that the $\gamma^{\prime}$ phase forming elements such as $\mathrm{Al}$ and Ta are enriched on the GB, and the element concentration decreases with the decrease of cooling rate. At a low cooling rate $\left(10^{\circ} \mathrm{C} \cdot \mathrm{min}^{-1}\right)$, $\mathrm{Al}$ and Ta elements on the GB preferably diffuse into the existing primary $\gamma^{\prime}$ phases at the front of GB. Finally, the $\gamma^{\prime}$ phase at the front of GB grows into the original matrix, and is perpendicular to GB. At the recrystallization GB, $\gamma^{\prime}$ phase cannot nucleate due to insufficient forming elements. Thus, a recrystallization GB layer is formed, as shown in Fig. 8(c).

\section{Conclusions}

The evolution mechanism of recrystallization in a nickel-based single crystal superalloy after heat treatment at $1,200{ }^{\circ} \mathrm{C}$ for $4 \mathrm{~h}$ with various cooling rates was studied, and the following conclusions are drawn:

(1) A continuous recrystallization layer is formed on the surface of a single crystal superalloy, and the average thickness of the recrystallization layer decreases with the increasing cooling rate.

(2) At a low cooling rate $\left(10{ }^{\circ} \mathrm{C} \cdot \mathrm{min}^{-1}\right)$, large size and small volume fractionof $\gamma^{\prime}$ phases are obtained in the recrystallization region. In contrast, small size and high volume fraction of $\gamma^{\prime}$ phases are formed in the recrystallization region under high cooling rates $\left(70,100{ }^{\circ} \mathrm{C} \cdot \mathrm{min}^{-1}\right)$.

(3) A grain boundary layer with a thickness of $400 \mathrm{~nm}$ is observed at a low cooling rate $\left(10^{\circ} \mathrm{C} \cdot \mathrm{min}^{-1}\right)$.

(4) The morphologies of the secondary $\gamma^{\prime}$ phase are cuboidal or triangular. Under the cooling rate of $70{ }^{\circ} \mathrm{C} \cdot \mathrm{min}^{-1}$, many irregular fine secondary $\gamma^{\prime}$ phases are precipitated between $\gamma$ matrix channels with an average size of $150 \mathrm{~nm}$. With the increase of cooling rate up to $100{ }^{\circ} \mathrm{C} \cdot \mathrm{min}^{-1}$, the size of the secondary $\gamma^{\prime}$ phases is decreased to $80 \mathrm{~nm}$.

\section{Acknowledgements}

This work was financially supported by the National Natural Science Foundation of China (No. 92060104), the National Science and Technology Major Project (No. 2017-VII-00080102), and the Shanghai Municipal Science and Technology Committee Grant (No. 20511107700).

\section{References}

[1] Pollock T, Tin S. Nickel-based superalloys for advanced turbine engines: Chemistry, microstructure and properties. J. Propulsion \& Power, 2006, 22(2): 361-374.

[2] Reed R C. The superalloy: Fundamentals and applications. FIrst Ed., New York: Cambridge University Press, 2006.

[3] Pan D, Xu Q Y, Liu B C, et al. Modeling of grain selection during directional solidification of single crystal superalloy turbine blade castings. JOM, 2010, 62(5): 30-34.

[4] Ma D X, Wu Q, Bührig-Polaczek A. Some new observations on freckle formation in directionally solidified superalloy components. Metall. Mater. Trans. B, 2012, 43(29): 344-353.

[5] Zhuo L C, Liu M, Chen $Q Y$, et al. Characterisation of surface recrystallisation in a grit-blasted single-crystal superalloy. Mater. Sci. Technol., 2017, 34(3): 1-6.

[6] Meng J, Jin T, Sun X F, et al. Surface recrystallization of a single crystal nickel-base superalloy. Int. J. Miner. Metall. Mater., 2011, 18(2): 197-202.

[7] Jo $C Y$, Kim H M. Effect of recrystallisation on microstructural evolution and mechanical properties of single crystal nickelbased superalloy CMSX-2 Part 2 - Creep behaviour of surface recrystallised single crystal. Mater. Sci. Technol., 2003, 19: 1671-1676.

[8] Zhang B, Liu C, Lu X, et al. Effect of surface recrystallization on the creep rupture property of a single-crystal superalloy. Rare Metals, 2010, 29: 413-416.

[9] Xie G, Wang L, Zhang J, et al. Influence of recrystallization on the high-temperature properties of a directionally solidified $\mathrm{Ni}$ base superalloy. Metall. Mater. Trans. A, 2008, 39(22): 206-210.

[10] Xie G, Lou L H. Influence of the characteristic of recrystallization grain boundary on the formation of creep cracks in a directionally solidified Ni-base superalloy. Mater. Sci. Eng. A, 2012, 532: 579-584.

[11] Xie G, Wang L, Zhang J, et al. Intermediate temperature creep of directionally solidified $\mathrm{Ni}$-based superalloy containing local recrystallization. Mater. Sci. Eng. A, 2011, 528(7-8): 3062-3068.

[12] Ma X F, Shi H J. In situ SEM studies of the low cycle fatigue behavior of DZ4 superalloy at elevated temperature: Effect of partial recrystallization. Int. J. Fatigue, 2014, 61: 255-263.

[13] Meng J, Jin T, Sun X F, et al. Effect of surface recrystallization on the creep rupture properties of a nickel-base single crystal superalloy. Mater. Sci. Eng. A, 2010, 527: 6119-6122.

[14] Ma X F, Jiang J S, Zhang W J, et al. Effect of local recrystallized grains on the low cycle fatigue behavior of a nickel-based single crystal superalloy. Crystals, 2019, 312, 1-12.

[15] Shi Z X, Liu S Z, Yue X D, et al. Effect of cellular recrystallization on tensile properties of a nickel-based single crystal superalloy containing Re and Ru. J. Iron Steel Res. Int., 2017, 21: 1059-1061.

[16] Xiong J C, Li J R, Liu S Z. Surface Recrystallization in nickel base single crystal superalloy DD6. Chin. J. Aeronaut., 2010, 23: 478-485

[17] Zambaldi C, Roters F, Raabe D, et al. Modeling and experiments on the indentation deformation and recrystallization of a singlecrystal nickel-base superalloy. Mater. Sci. Eng. A, 2007, 454455: 433-440. 
[18] Xie G, Wang W, Zhang J, et al. Orientational dependence of recrystallization in an Ni-base single-crystal superalloy. Scr. Mater., 2012, 66(6): 378-381.

[19] Wang L, Xie G, Lou L H. Effect of carbon content on the recrystallization of a single crystal nickel-based superalloy. Mater. Lett., 2013, 109: 154-157.

[20] Wang L, Xie G, Zhang J, et al. On the role of carbides during the recrystallization of a directionally solidified nickel-base superalloy. Scr. Mater., 2006, 55(5): 457-460.

[21] Li Z L, Xu Q Y, Liu B C. Experimental investigation on recrystallization mechanism of a $\mathrm{Ni}$-base single crystal superalloy. J. Alloy. Compd., 2016, 672: 457-469.

[22] Cox D C, Roebuck B, Rae C M F, et al. Recrystallisation of single crystal superalloy CMSX-4. Mater. Sci. Technol., 2003, 19: 440-446.

[23] Liu W W, Tang D Z. Effect of cooling rate after solution on microstructure and creep properties of single crystal superalloy DD3. Rare Metals, 2011, 30: 396-400.

[24] Wang XY, Li M, Wen ZX. The effect of the cooling rates on the microstructure and high-temperature mechanical properties of a nickel-based single crystal superalloy. Materials, 2020, 13: 4256.

[25] Wang L, Pyczak F, Zhang J, et al. Effect of eutectics on plastic deformation and subsequent recrystallization in the single crystal nickel base superalloy CMSX-4. Mate. Sci. Eng. A, 2012, 532: 487-492.

[26] Su X L, Xu Q Y, Wang R N, et al. Microstructural evolution and compositional homogenization of a low Re-bearing Ni-based single crystal superalloy during through progression of heat treatment. Mate. Des., 2018, 141: 296-322.

[27] Wen Z X, Zhang D X, Li S W, et al. Anisotropic creep damage and fracture mechanism of nickel-base single crystal superalloy under multiaxial stress. J. Alloy. Compd., 2017, 692: 301-312.

[28] Huang G C, Liu G Q, Feng M N, et al. The effect of cooling rates from temperatures above the $\mathrm{Y}^{\prime}$ solvus on the microstructure of a new nickel-based powder metallurgy superalloy. J. Alloy. Compd., 2018, 747: 1062-1072.
[29] Wang L, Jiang W G, Lou L H. The deformation and the recrystallization initiation in the dendrite core and interdendritic regions of a directionally solidified nickel-based superalloy. J. Alloy. Compd., 2015, 629: 247-254.

[30] Song X, Rettenmayr M, Müller C, et al. Modeling of recrystallization after inhomogeneous deformation. Metall. Mater. Trans. A, 2001, 32(9): 2199-2206.

[31] Li Z, Xu Q, Liu B. Microstructure simulation on recrystallization of an as-cast nickel based single crystal superalloy. Comput. Mater. Sci., 2015, 107: 122-133.

[32] Humphreys F J, Hatherly M. Recrystallization and related annealing phenomena. 2nd edition, Elsevier, Oxford, 2004.

[33] Sieradzki L, Madej L. A perceptive comparison of the cellular automata and Monte Carlo techniques in application to static recrystallization modeling in polycrystalline materials. Comput. Mater. Sci., 2013, 67: 156-173.

[34] Yu Y N. Principles of metallography. Beijing: Metallurgical Industry Press, 2005. (In Chinese)

[35] Arabi H, Rastegari S, Mirhosseini M, et al. Effect of cooling rates from partial solution temperature and aging on $\mathrm{Y}^{\prime}$ precipitation in IN792 superalloy. Mater. Sci. Technol., 2013, 29: 1513-1517.

[36] Mao J, Chang K M, Yang W H, et al. Cooling precipitation and strengthening study in powder metallurgy superalloy Rene88DT. Mater. Sci. Eng. A, 2002, 332: 318-329.

[37] Masoumi F, Jahazi M, Shahriari D, et al. Coarsening and dissolution of $\mathrm{y}^{\prime}$ precipitates during solution treatment of AD730TM Ni-based superalloy: Mechanisms and kinetics models. J. Alloy. Compd., 2016, 658: 981-995.

[38] Baldan A. Review progress in Ostwald ripening theories and their applications to nickel-base superalloys Part I: Ostwald ripening theories. J. Mater. Sci., 2002, 37: 2171-2202. 